\title{
Comments concerning the real risk of sexual adverse events secondary to the use of 5-ARIs
}

\author{
Furio Pirozzi Farina, Antonella Pischedda \\ Andrological Urology Unit, AOU di Sassari.
} \begin{abstract}
$\begin{array}{ll}\text { Summary } & \text { Treatment-induced sexual dysfunctions } \\ \text { (SD) are a recurrent and controversial }\end{array}$ topic in recent literature on the adverse events related to the use of 5-alpha-reductase inhibitors (5ARIs) $(1,2)$. In order to deal adequately with the various aspects of this topic, it is necessary to first cover some of the steps that allow a better definition and understanding of the subject.
\end{abstract}

KEY WORDS: 5-alpha-reductase inhibitors (5ARIs); Sexual dysfunctions; Benign prostatic hyperplasia (BPH); Androgenetic alopecia.

Submitted 9 November; Accepted 15 December

\section{5- $\alpha$-REDUCTASES AND THEIR INHIBITORS}

5 - $\alpha$-reductases are enzymes able to reduce the 4,5 bond of C19 and C21 steroids, to create the $5 \alpha$-reduced steroid of a precursor steroid (3). Two of this type of isoenzyme are known: $5 \alpha$-R typel ( $5 \alpha-\mathrm{R} 1)$ and $5 \alpha$-R type 2 ( $5 \alpha-\mathrm{R} 2)$ (3). Both isoenzymes trigger the chain of events that lead to the synthesis of other steroids, of which the best known is $5 \alpha$-dihydrotestosterone ( $5 \alpha$-DHT) (3).

$5 \alpha$-DHT is the most active androgen in certain expressions of male sexuality (4) and it is also the most involved hormone in prostate gland function and dysfunction. (5) In addition, the many roles played by $5 \alpha$-DHT also include a direct involvement in the tone of the scalp's piliferous bulbs (6). Consequently, the induction of a reduction in the activity of 5- $\alpha$-reductase, through the administration of 5ARIs, is a treatment approach useful in the treatment of benign prostatic hyperplasia (BPH) (7) and androgenetic alopecia (8), as both diseases are related to $5 \alpha$-DHT. However, at the same time, this treatment also theoretically exposes the subject to repercussions in terms of various expressions of male sexuality.

The $5 \alpha$-RIs used for therapy are finasteride and dutasteride. Dutasteride is a selective inhibitor of $5 \alpha-R 1$ and $5 \alpha-\mathrm{R} 2$ and reduces serum $5 \alpha$-DHT by approximately $90 \%$ (9). Finasteride is above all an inhibitor of $5 \alpha-\mathrm{R} 2$ and is approximately 50 times weaker in inhibiting $5 \alpha$ $\mathrm{R} 1$ than $5 \alpha$-R2; for this reason, finasteride is able to reduce serum $5 \alpha$-DHT by about $70 \%$ (9).

\section{INDICATIONS FOR TREATMENT WITH $\mathbf{5} \boldsymbol{\alpha}$-R INHIBITORS}

The $5 \alpha$-RIs finasteride and dutasteride were developed for the treatment of patients with urinary disorders sec- ondary to BPH with a high risk of progression, in order to reduce the incidence of the risks connected with disease progression (10). These risks consist in acute urinary retention (AUR) and in the need for surgical treatment for prostatic adenoma (11).

Over the years, a great number of patients have benefitted from treatment with 5ARIs, especially those with progressing BPH (11). A number of studies performed on patients with $\mathrm{BPH}$ treated with $5 \alpha$-RIs have reported positive effects such as a reduction in prostatic volume, an improvement in IPSS questionnaire scores, an improvement in urinary flow, a reduction in the risk of acute urinary retention and, most importantly, a reduction in the number of patients having to undergo surgical treatment or other invasive or minimally-invasive treatments for $\mathrm{BPH}(11,12)$. However, these therapies allegedly have a high risk of important and irreversible side effects that also involve the sexual area (1).

In addition to this, finasteride has also been approved for the treatment of Androgenetic Alopecia (AGA) or male pattern baldness, which affects about $50 \%$ of males (13).

\section{SeXual ADVERSE EVENTS OF TREATMENT WITH $\mathbf{5} \alpha-\mathbf{R}$ INHIBITORS (ALSO KNOWN AS POST-FINASTERIDE SYNDROME)}

There are increasingly frequent reports of problems that the use of $5 \alpha$-RIs (finasteride and dutasteride) may cause to sexual health in a subgroup of patients; in some cases, these problems would appear to persist even after the discontinuation of treatment $(14,15)$.

However, there are still very few studies on this subject and knowledge is based either on scientific concepts or on case reports submitted by general practitioners and based on reports by patients (16).

In actual fact, a study by Erdemir F, et al. (2008) reported that the 5ARIs used to treat BPH, caused erectile dysfunction and/or a loss of libido with an incidence of less than $10 \%$, for both monotherapy and combination therapy (dutasteride + tamsulosin). (17) In this same paper, the Authors reported that finasteride- and dutasterideinduced sexual dysfunction resolved completely when treatment was discontinued and that, in any case, in approximately $4 \%$ of patients, treatment was discontinued due to sexual adverse events. (17)

The size of the problem was further put into perspective 
by a recent literature review by Abdulmaged MT, et al. (2011), in which the finding of sexual adverse events attributed to the use of $5 \alpha$-RIs is compared with data relating to the use of placebo (2). The findings of this review can be summarised as follows: erectile dysfunction $6 \%-8 \%$ vs. $4 \%$ with placebo; loss/reduction in libido $1.3 \%-4.4 \%$ vs. $1.8 \%$ with placebo and ejaculatory disorders $2.8 \%$ vs. $1 \%$ with placebo (2).

As far as the persistence of sexual adverse events is concerned, an important finding was reported by the Medicine Health Care Products Regulatory Agency (MHRA), which, in its 2009 report states, that "... in postmarketing experience, in certain patients the ED that appeared with the introduction of Propecia is thought to persist even after discontinuation of the medicinal product". (Medicine Health Care Products Regulatory Agency (MHRA - December 2009 sect. 4.8)

However, again on the subject of alopecia, Sato and Takeda (2012) conducted a study on the efficacy and safety of finasteride $1 \mathrm{mg}$ administered for 41 months in 3177 patients with androgenetic alopecia, concluding that the treatment allowed progressive hair growth without any side effects being observed (18).

In this contradictory series of data, it can be said that the nature of the persistence of these disorders is still an active field of research. Therefore, as a precautionary measure, both doctors prescribing $5 \alpha$-RIs, and patients taking this class of drugs, must be made aware of the potential permanent sexual adverse events that could, according to certain Authors, be related to them (19).

At this point, the question is: if the reduction in $5 \alpha-$ DHT induced by $5 \alpha$-RIs is a sufficient condition to cause sexual dysfunction which, in some cases, can be permanent, why does this not occur in all patients treated, and in particular in those in whom normal sexual function was confirmed prior to treatment? Amongst the various hypotheses, it is possible that the answer should be sought in the genetic differences existing between individuals, such as postulable $5 \alpha$-reductase polymorphisms, which could contribute to an inter-individual variability in the response to $5 \alpha$-RIs (20).

Regardless of the cause and actual incidence of the risk of sexual adverse events in patients treated with $5 \alpha$-RIs, both clinical and ethical importance undoubtedly vary with the age of patients and the condition for which the $5 \alpha$-RIs are used. For this reason, it is believed that the chronic administration of finasteride $1 \mathrm{mg}$ in young patients with androgenetic alopecia (AGA) constitutes a "cosmetic" treatment, although it is also sometimes prescribed to minimise the relational psychological repercussions that hair loss can have.

On the other hand, a comparison must be made between the risk of sexual adverse events deriving from the use of $5 \alpha$-RIs (alone or combined with alpha adrenergic blockers) in patients with lower urinary tract symptoms secondary to BPH at a high risk of progression, and the far more pressing issue of important sexual and other adverse events deriving from the underlying prostatic condition (Acute Urinary Retention, BPH Surgery-related symptoms and Clinical Progression), and the treatment options for BPH that are alternative to $5 \alpha$-RIs.

Specifically, the awareness of all the potential adverse events related to invasive and minimally invasive treatments for BPH is very important (21).

This balance is well expressed in two pivotal studies conducted on a large number of patients with BPH treated with dutasteride $0.5 \mathrm{mg}$ + tamsulosina $4 \mathrm{mg}$ (CombAT study) (22) and with finasteride $5 \mathrm{mg}$ (PLESS study) (23).

CombAT study (dutasteride $0.5 \mathrm{mg}$ and tamsulosina 4 $\mathrm{mg}$, in combination or monotherapy); $4844 \mathrm{Pt}$ ( $\geq 50$ years) observed for 4 years. (22)

The study was conducted to evaluate the efficacy of the therapy with dutasteride and tamsulosin, administered as monotherapy or in combination, in the prevention of major complications secondary to BPH: disease progression, acute urinary retention (AUR), BPH-related surgery (22). This study showed that combination treatment with dutasteride + tamsulosin significantly reduces the relative risk of AUR and BPH-related surgery (primary endpoint at four years) compared to monotherapy with tamsulosin (22).

This study also showed that the incidence of Adverse Events in the Sexual Field (ED) drops with the years of use of treatment (22 \& Avodart European Summary of Product Characteristics - February 2011).

PLESS Study (The Proscar Long-Term Efficacy and Safety Study); 3040 Pt. (45-78 years), observed for 4 years, RCT, finasteride vs. placebo (23).

- At screening, $46 \%$ of patients in both groups said they had a history of Sexual Dysfunction (SD) (23)

- The sexual side effects were only significant during the first year (15\% vs. $7 \%$ ) (23)

- There were no significant differences between the second and the fourth year (7\% in both groups) (23)

- Only 4\% of patients treated with finasteride and 2\% of patients treated with placebo interrupted the study due to sexual adverse events (23)

- $50 \%$ of patients treated with finasteride said the SD persisted after the suspension of the treatment (23)

- $59 \%$ of patients treated with placebo said the SD persisted after the suspension of the treatment (23)

To conclude, on the subject of sexual adverse events, the results of this study can be summarised by stating that there is a low and equivalent prevalence of adverse events at 2-4 years with both finasteride and placebo, and that $59 \%$ of patients treated with placebo who suspended use due to sexual adverse events, reported persistent sexual dysfunction (23).

\section{THE "NOCEBO" EFFECT OF TREATMENT WITH $5 \boldsymbol{\alpha}$-R INHIBITORS}

The numerous contradictions that emerge from recent literature concerning the presumed sexual repercussions observed in certain groups of patients treated with $5 \alpha$ RIs, arouse doubts as to the methods used to investigate the parameters of sexual health in patients eligible for treatment with $5 \alpha$-RIs. Specifically, this applies for an adequate definition of the parameters of sexual health (libido, erection, ejaculation) immediately prior to the start of treatment with $5 \alpha$-RIs. 
Table 1.

\begin{tabular}{|c|c|c|c|c|c|c|c|c|}
\hline Study patients & $\begin{array}{c}\text { (\%) SAE } \\
\text { at } 6 \text { months }\end{array}$ & $\begin{array}{l}(\%) \text { SAE } \\
\text { at } 1 \text { year }\end{array}$ & $\begin{array}{c}\text { (\%) ED } \\
\text { at } 6 \text { months }\end{array}$ & $\begin{array}{c}\text { (\%) ED } \\
\text { at } 1 \text { year }\end{array}$ & $\begin{array}{l}\text { (\%) Diminished } \\
\text { libido at } 6 \text { months }\end{array}$ & $\begin{array}{l}\text { (\%) Diminished } \\
\text { libido at } 1 \text { year }\end{array}$ & $\begin{array}{c}\text { (\%) Ejaculated } \\
\text { disorder at } 6 \text { months }\end{array}$ & $\begin{array}{c}\text { (\%) Ejaculated } \\
\text { disorder at } 1 \text { year }\end{array}$ \\
\hline All patients $(\mathrm{N}=107)$ & $24.3 \%$ & 29.90 & $15.8 \%$ & $20.5 \%$ & $11.2 \%$ & $15.8 \%$ & $8.4 \%$ & $11.2 \%$ \\
\hline Group $2(\mathrm{~N}=55)$ & $36.3 \%$ & 43.6 & $25.4 \%$ & 30.9 & $18.1 \%$ & 23.6 & $10.9 \%$ & 16.3 \\
\hline
\end{tabular}

Moreover, the Sexual Medicine Society of North America has reported that treatment with $5 \alpha$-RIs is associated with sexual side effects that can persist even after the discontinuation of the treatment; however, it specifies that, at the current time, there are no proven causal connections between $5 \alpha$-RIs and the symptoms of sexual dysfunction reported by patients, and therefore further studies on the matter are required (24).

This suggests that doctors could perceive a greater incidence of sexual adverse events in clinical practice than observed during clinical trials, although there is currently no objective evidence of this greater incidence.

Moreover, a potential "nocebo effect" has been proven that could be attributed to the ways in which patients are informed about the use of $5 \alpha$-RIs. To investigate this, Mondaini N, et al. (2007) studied 120 patients with $\mathrm{BPH}$ and IIEF-EF score $\geq 25$ treated for one year with $5 \mathrm{mg}$ of finasteride, masked as "compound $X$ with proven efficacy for the treatment of BPH". Patients were assigned to two groups (26).

Those in group 1 did not received information about the possible sexual repercussions of the drug; patients in group 2, on the other hand, were provided with the following information: "... may cause erectile dysfunction, loss of libido and ejaculation disorders, however these are not common'. (26) All the patients were evaluated at 6 and 12 months using the male sexual function questionnaire -4 (MSF4). The Authors' results are provided below (Table1) (26)

On the basis of these results, the Authors concluded that patients in group 2 simulate the side effects indicated in medical information and in the information leaflet, which would suggest that the information/illustration has a nocebo effect (26).

\section{HOW TO OPTIMISE THE MEDICAL TREATMENT OF BPH AND OF THE RELATED URINARY SYMPTOMS}

At the current time, the optimisation of medical treatment for lower urinary tract symptoms secondary to BPH consists in knowing how to create the most individualised treatment plan possible. This means setting oneself the following objectives: minimising dysuria symptoms; stopping or slowing BPH when at high risk of progression, avoiding or delaying the surgical solution; safeguarding the patient's sexual health in the best way possible; as far as possible following the wishes of the patient, who must in any case receive comprehensible information on the mechanism of action of the drugs suggested, the incidence of any events that can be attributed to the various therapies and their reversibility before starting treatment.
On this basis, at least three main patient classes can be summarised:

Patients with BPH-related lower urinary tract symptoms at low risk of progression.

In this type of patient, a first therapeutic approach could be $\alpha 1 \mathrm{~A}$ adrenergic blocker monotherapy when the urinary symptoms are not associated with pre-existent erectile dysfunction (ED). Otherwise, it is possible to suggest treatment with the PDE5-inhibitor tadalafil $5 \mathrm{mg}$ once daily, a treatment regimen approved for patients with $\mathrm{BPH}$ with obstructive symptoms of the lower urinary tract, with or without ED (27).

\section{Patients with BPH-related lower urinary tract symp-} toms at high risk of progression.

In this class of patients the ideal treatment approach is $5 \alpha$-RI prescription. The drugs can be administered as monotherapy or, in order to obtain a faster and more beneficial therapeutic result on symptoms, the $5 \alpha$-RI dutasteride can be prescribed in combination with an $\alpha 1$ A-adrenergic blocker (22). Moreover, as the PDE5inhibitor tadalafil $5 \mathrm{mg}$ once daily has been approved for the treatment of obstructive lower urinary tract symptoms secondary to BHP (27), the $5 \alpha$-RI dutasteride can, currently, be suggested in combination with tadalafil 5 mg once daily, with or without concomitant ED (28).

Patients with BPH-related lower urinary tract symptoms at high risk of progression and concomitant ED.

The simultaneous administration of tadalafil and finasteride would appear to allow a rapid improvement in obstructive and irritation symptoms of the lower unit urinary tract in men with BPH (29). Tadalafil co-administered with finasteride is also thought to improve erectile function in those men with concomitant erectile dysfunction (29).

Regardless of the treatment prescribed or proposed - as a general rule the fully reimbursed agents are prescribed and those not reimbursed are proposed - appropriately timed regular clinical monitoring is required (1-3-6-12 months). The aim of this is to monitor the results of treatment, evaluate any adverse events and, ultimately, prevent, approximately every 12 months, the incidental overlap of prostatic cancer.

The evaluation of any adverse events and, in particular, sexual adverse ones, cannot exclude a careful investigation of the conditions of the patient before starting therapy and the implications that may be determined by the nocebo effect described above. In this sense, it is essential to administer dedicated questionnaires (e.g. IIEF- 
IPSS) and to perform endocrinological tests before and during treatment.

As with any other treatment, in the case of adverse events, in addition to reporting them to the appropriate Authority, their relationship with the $5 \alpha$-RIs must be verified and, where appropriate, solutions must be devised. In addition to this, the patient must be reassured of the fact that he will in any case be helped to overcome the problem.

\section{Conclusions}

The most recent literature review conducted by Trost $L$ et al. (2013) including over 62,827 patients, showed a slight increase in the rate of loss of libido, of ED, and ejaculatory disorders in patients taking $5 \alpha$-RIs and placebo (1.5\% 1.6\% 3.4\%, and 1.3\% respectively) (1). The Authors of this review conclude that further studies are required using validated questionnaires, to establish the real prevalence, clinical relevance and potential longterm persistence of adverse effects related to the use of $5 \alpha$-RIs (1).

As regards the information to be given to patients before starting treatment with $5 \alpha$-RIs, the doctor must illustrate, in a certainly comprehensible manner, the rationale and expected benefits of the therapy: a reduction in the risk of BPH progression; a reduction in the risk of AUR; an improvement in urinary symptoms; a reduction in the risk of the need for surgical treatment. The doctor must also illustrate the potential onset of side effects related to the use of $5 \alpha$-RIs. As far as the assessment of sexual adverse events is concerned, the doctor must thoroughly investigate the various aspects of the individual's basic sexual function, before starting treatment. In addition to this, the doctor must always remember the importance of the documented nocebo effect and appropriate counselling must be provided in order to reassure the patient that he will receive help in overcoming any sexual problems that, for whatever reason, may arise during treatment. Medical treatment for lower urinary tract symptoms associated with BPH must be as individualised as possible. This ranges from monotherapy with $\alpha 1 \mathrm{~A}$-adrenergic blockers, to that with $5 \alpha$-RIs when BPH is at risk of progression. A beneficial synergetic therapeutic effect has been observed for combinations of $5 \alpha$ RIs and $\alpha 1 \mathrm{~A}$-adrenergic blocker (tamsulosin and dutasteride). A new alternative to this solution is treatment with the PDE5-inhibitor tadalafil that, both in monotherapy and in combination with the $5 \alpha$-RIs, provides advantages in the treatment of lower urinary tract symptoms secondary to BPH, especially with concomitant ED and in the treatment of lower urinary tract symptoms secondary to BPH at risk of progression, especially when associated with ED.

\section{REFERENCES}

1. Trost L, Saitz BS, Hellstrom WJG. Side effects of 5-Alpha Reductase Inhibitors: A Comprehensive Review. Sex Med Rev. 2013; 1:21-41.

2. Abdulmaged MT, Hassani JMA, Guay AT, et al. Adverse Side
Effects of $5 \boldsymbol{\alpha}$-Reductase Inhibitors Therapy: Persistent Diminished Libido and Erectile Dysfunction and Depression in a Subset of Patients J Sex Med. 2011; 8:872-884.

3. Russell DW, Wilson JD. Steroid 5 alpha-reductase: two genes/two enzymes. Annu Rev Biochem. 1994; 63:25-61.

4. Arteaga-Silva M, Vigueras-Villaseñor RM, Retana-Márquez S, et al. Testosterone, androstenedione, and $5 \alpha$-dihydrotestosterone on male sexual behavior and penile spines in the hamster. Physiology $\&$ Behavior 2008; 94: 412-421.

5. Bartsch G, Rittmaster RS, Klocker H. Dihydrotestosterone and the concept of 5alpha-reductase inhibition in human benign prostatic hyperplasia. World J Urol. 2002; 19:413-25.

6. Urysiak-Czubatka I, Kmiec ML, Broniarczyk-Dyła G. Assessment of the usefulness of dihydrotestosterone in the diagnostics of patients with androgenetic alopecia. Postepy Dermatol Alergol. 2014; 31:207-15.

7. Park T, Choi JY. Efficacy and safety of dutasteride for the treatment of symptomatic benign prostatic hyperplasia (BPH): a systematic review and meta-analysis. World J Urol. 2014; 32:1093-105.

8. Yim E, Nole KL, Tosti A. $5 \alpha$-Reductase inhibitors in androgenetic alopecia. Curr Opin Endocrinol Diabetes Obes. 2014; 21:493-8.

9. Bartsch G, Rittmaster RS, Klocker H. Dihydrotestosterone and the concept of 5alpha-reductase inhibition in human benign prostatic hyperplasia. World J Urol. 2002; 19:413-25.

10. McConnell JD, Bruskewitz R, Walsh P, et al. The effect of finasteride on the risk of acute urinary retention and the need for surgical treatment among men with benign prostatic hyperplasia. Finasteride Long-Term Efficacy and Safety Study Group. N Engl J Med. 1998; 338:557-63.

11. Roehrborn CG, Boyle P, Nickel JC, et al. Efficacy and safety of a dual inhibitor of 5-alpha-reductase types 1 and 2 (dutasteride) in men with benign prostatic hyperplasia. Urology. 2002; 60:434-41.

12. McConnell JD, Bruskewitz R, Walsh R, et al. The effect of finasteride on the risk of acute urinary retention and the need for surgical treatment among men with benign prostatic hyperplasia. Finasteride Long-Term Efficacy and Safety Study Group. N Engl J Med. 1998; 338:557-63.

13. Otberg N, Finner AM, Shapiro J. Androgenetic alopecia. Endocrinol Metab Clin North Am. 2007; 36:379-98.

14. Traish AM, Hassani J, Guay AT, et al. Adverse side effects of $5 \alpha$-reductase inhibitors therapy: persistent diminished libido and erectile dysfunction and depression in a subset of patients. J Sex Med. 8:872-84.

15. Irwig MS, Kolukula S. Persistent sexual side effects of finasteride for male pattern hair loss. J Sex Med. 2011; 8:1747-53.

16. Trost L, Saitz TR, Hellstrom WJG. Side effects of 5-Alpha Reductase Inhibitors: A Comprehensive Review. Sex Med Rev. 2013; 1:24-41.

17. Erdemir F, Harbin A, Hellstrom WJ. 5-alpha reductase inhibitors and erectile dysfunction: the connection. J Sex Med. 2008; 5:2917-24.

18. Sato A, Takeda A. Evaluation of efficacy and safety of finasteride $1 \mathrm{mg}$ in 3177 Japanese men with androgenic alopecia. Dermatol. 2012; 39:27-32.

19. Irwing MS. Persistent Sexual Side Effects of Finasteride: Could They be Permanent? J Sex Med. 2012; 9:2927-293.

20. Elzanaty S, Giwercman YL, Giwercman A. Significant impact of 
5alpha-reductase type 2 polymorphisms on sperm concentration and motility Int. J Androl. 2006; 29:414-420.

21. AUA Guideline: Managemant of Benign Prostatic Hyperplasia (BPH); Panel Members: KT McVary (Chair), CG Roehrborn (Cochair), et al.; Copyright 2010 American Urological Association Education and Research, Inc ${ }^{\circledR} ; 1-496$

22. Roehrborn CG, Siami P, Barkin J, et al. CombAT Study Group. The effects of combination therapy with dutasteride and tamsulosin on clinical outcomes in men with symptomatic benign prostatic hyperplasia: 4-year results from the CombAT study. Eur Urol. 2010; 57:123-31.

23. Wessels H, Roy J, Bannow J, et al. Incidence and severity of sexual adverse experiences in finasteride and placebo treated men with benign prostatic hyperplasia. Urology. 2003; 61:579-84.

24. FDA Warns Men of Serious Side Effects from These Drugs-But Keeps Them on the Market (http://www.fda.gov/drugs/drugsafety/ informationbydrugclass/ucm299754.htm)

25. Seftel A, Rosen R, Kuritzky L. Physician perceptions of sexual dysfunction related to benign prostatic hyperplasia (BPH) symptoms and sexual side effects related to $\mathrm{BPH}$ medications International Journal of Impotence Research. 2007; 19:386-392.

26. Mondaini N, Gontero P, Giubilei G, et al. Bartoletti. Finasteride $5 \mathrm{mg}$ and sexual side effects: how many of these are related to a nocebo phenomenon? J Sex Med. 2007; 4:1708-12.

27. European Medicines Agency. 18 October 2012 EMA/647346/ 2012 Committee for Medicinal Products for Human Use (CHMP). Assessment report Cialis tadalafil Procedure No. EMEA/H/C/ 000436/II/0060

28. Volkov AA, Petrichko MI, Budnik NV. Correction of erectile dysfunction in patients with benign prostate hyperplasia using daily administration of tadalafil $5 \mathrm{mg}$ against the background of combined drug therapy. Urologiia. 2013; 54:50-2.

29. Casabé A, Roehrborn CG, Da Pozzo LF, et al. Efficacy and safety of the coadministration of tadalafil once daily with finasteride for 6 months in men with lower urinary tract symptoms and prostatic enlargement secondary to benign prostatic hyperplasia. J Urol. 2014; 191:727-33.

\section{Correspondence}

Antonella Pischedda, MD

Furio Pirozzi Farina, (Corresponding Autor) andro@tin.it

Associate Professor of Urology - Università di Sassari Specialist in Urology and Andrology

Director, Department of Andrological Urology - AOU di Sassari

Via Matteotti, 14 - Sassari, Italy 